\title{
Aspectos anatomopatológicos e avaliação de agentes infecciosos em 32 gatos com colângio-hepatite ${ }^{1}$
}

\author{
Fernando F. Argenta², Veronica M. Rolim² , Cíntia de Lorenzo², \\ Gustavo Geraldo M. Snel' ${ }^{2}$, Saulo P. Pavarini² ${ }^{2}$ Luciana Sonne ${ }^{2}$ e David Driemeier ${ }^{2 *}$
}

\begin{abstract}
Argenta F.F., Rolim V.M., Lorenzo C., Snel G.G.M., Pavarini S.P., Sonne L. \& Driemeier D. 2018. [Anatomopathological aspects and determination of infectious agents in 32 cats with cholangiohepatitis.] Aspectos anatomopatológicos e avaliação de agentes infecciosos em 32 gatos com colângio-hepatite. Pesquisa Veterinária Brasileira 38(5):920-929. Setor de Patologia Veterinária, Departamento de Patologia Clínica Veterinária, Faculdade de Veterinária, Universidade Federal do Rio Grande do Sul, Av. Bento Gonçalves 9090, Prédio 42505, Porto Alegre, RS 91540-000, Brazil. E-mail: davetpat@ufrgs.br

Cholangiohepatitis is considered a frequent cause of liver failure in cats, and are classified as neutrophilic, lymphocytic and sclerosing. The aims of this study was to determine the frequency of cholangiohepatitis in cats diagnosed in the metropolitan region of Porto Alegre, to describe the anatomopathological aspects and to establish an association with Escherichia coli, feline immunodeficiency virus (FIV) and feline leukemia virus (FeLV). From January 2000 to July 2016, the Department of Veterinary Pathology of the Universidade Federal do Rio Grande do Sul performed 1915 cat necropsies, of which 32 were diagnosed with cholangiohepatitis, representing $1.7 \%$ of the cases. Of these, lymphocytic cholangiohepatitis $(\mathrm{LCH})$ was diagnosed in $68.7 \%(22 / 32)$, neutrophilic $(\mathrm{NCH})$ in $21.9 \%(7 / \mathrm{v})$ and sclerosing cholangiohepatitis $(\mathrm{SCH})$ with $9.4 \%(3 / 32)$ of the cases. In general, age ranged from four months to 16 years, with the median age of six years, and predominantly affected cats with mixed breed. Only in NCH demonstrated male predisposition, verified in 85.7\% (6/7) of this cases. Enteritis and pancreatitis were identified concomitantly with cholangiohepatitis in $56.2 \%(18 / 32)$ cases, each, and triad formation was identified in $46.9 \%(15 / 32)$ of cats. In the immunohistochemistry, we observed that $68.2 \%(15 / 22)$ of the cats with LCH were positive for FIV, 40.9\% (9/22) for FeLV, and 31.8\% (7/22) positive for both retroviruses. In NCH, 85.7\% (6/7) was positive for FIV, 57.1\% (4/7) for FeLV, and 42.8\% (3/7) immunoreactions for the two retroviruses. In SCH, 100\% (3/3) of the cases presented FeLV marking, 33.3\% $(1 / 3)$ for $\mathrm{FIV}$ and $33.3 \%(1 / 3)$ for both. Immunostaining for $E$. coli was observed in $27.3 \%$ (6/22) of LCH, 28.6\% (2/7) of NCH, and 33.3\% (1/3) of SCH. E. coli, Enterococcus sp. and Klebsiella pneumoniae were the most frequently microorganisms isolated in the bacteriological examination. The visualization of $E$. coli by the immunohistochemistry in the hepatobiliary system of cats diagnosed with cholangiohepatitis suggests that the disease developed secondary to ascending bacterial infection.
\end{abstract}

INDEX TERMS: Cholangiohepatitis, hepatobiliary disease, cholangitis, feline immunodeficiency virus, feline leukemia virus, Escherichia coli, cats, pathology.

RESUMO.- A colângio-hepatite é considerada uma causa frequente de insuficiência hepática em gatos e é classificada em neutrofílica, linfocítica e esclerosante. Os objetivos deste

\footnotetext{
${ }^{1}$ Recebido em 8 de março de 2017.

Aceito para publicação em 17 de abril de 2017.

${ }^{2}$ Setor de Patologia Veterinária, Departamento de Patologia Clínica Veterinária, Faculdade de Veterinária, Universidade Federal do Rio Grande do Sul (UFRGS), Av. Bento Gonçalves 9090, Porto Alegre, Prédio 42505, Porto Alegre, RS 91540-000, Brasil. *Autor para correspondência: davetpat@ufrgs.br
}

estudo foram determinar a frequência de colângio-hepatite em gatos diagnosticados na Região Metropolitana de Porto Alegre, descrever seus aspectos anatomopatológicos e estabelecer uma associação com as infecções por Escherichia coli, vírus da imunodeficiência felina (FIV) e vírus da leucemia felina (FeLV). No período de janeiro de 2000 a julho de 2016 o Setor de Patologia Veterinária da Universidade Federal do Rio Grande do Sul realizou 1915 necropsias de gatos, destes, 32 foram diagnosticados com colângio-hepatite, representando 
1,7\% dos casos. Destes, a colângio-hepatite linfocítica (CHL) foi diagnosticada em 68,7\% (22/32), a neutrofílica (CHN) em $21,9 \%(7 / 32)$ e a esclerosante (CHE) com 9,4\% (3/32). A idade variou de quatro meses a 16 anos, com a mediana de seis anos, acometendo predominantemente gatos sem raça definida. Somente na $\mathrm{CHN}$ observou-se predisposição por machos, verificado em 85,7\% (6/7) dos casos. Enterite e pancreatite foram identificadas concomitantemente com a colângio-hepatite em 56,2\% (18/32) dos casos, cada, e a formação de tríade foi identificada em 46,9\% (15/32) dos gatos. Através da imuno-histoquímica, 68,2\% (15/22) dos gatos com CHL, foram positivos para FIV, 40,9\% (9/22) para FeLV e 31,8\% (7/22) marcação para ambos os retrovírus. $\mathrm{Na} \mathrm{CHN}, 85,7 \%(6 / 7)$ positivos para FIV, 57,1\% (4/7) para FeLV e 42,8\% (3/7) imunorreação para os dois retrovírus. Na CHE, 100\% (3/3) dos casos apresentaram marcação para FeLV, 33,3\% (1/3) para FIV e 33,3\% (1/3) para ambos. Imunomarcação para $E$. coli foi observada em $27,3 \%(6 / 22)$ dos casos da CHL, 28,6\% (2/7) da CHN e em 33,3\% (1/3) da CHE. E. coli, Enterococcus sp. e Klebsiella pneumoniae foram os micro-organismos mais frequentes isolados no exame bacteriológico. A visualização da E. coli, através da IHQ no sistema hepatobiliar de gatos diagnosticados com colângio-hepatite associados à inflamação, sugere que a doença se desenvolveu secundariamente à infecção bacteriana ascendente.

TERMOS DE INDEXAÇÃO: Colângio-hepatite, doença hepatobiliar, colangite, vírus da imunodeficiência felina, vírus da leucemia felina, Escherichia coli, felinos, patologia.

\section{INTRODUÇÃO}

A colângio-hepatite consiste na inflamação dos ductos biliares e do parênquima hepático circunjacente e é considerada uma causa frequente de insuficiência hepática em gatos (Cullen \& Brown 2013, Barros 2016). Três formas dessa doença são reconhecidas com base nos aspectos histológicos, e são classificadas em neutrofílica (CHN), linfocítica (CHL) e esclerosante (CHE) (Cullen \& Stlaker 2016). A infecção bacteriana ascendente é provavelmente uma das causas dessa doença e Escherichia coli a mais frequente nestes casos (Day 1995, Cullen \& Stlaker 2016). Em alguns casos observam-se, simultaneamente, lesões inflamatórias no pâncreas, intestino e sistema hepatobiliar, caracterizando a tríade felina (Weiss et al. 1996, Cullen \& Brown 2013, Cullen \& Stlaker 2016). Processos imunomediados, colelitíase, trematódeos hepatobiliares, protozoários e síndrome nefrótica também têm sido apontados como fatores envolvidos na patogenia dessa doença (Day 1995, Barros 2016). Clinicamente, observam-se sinais de insuficiência hepática, caracterizadas, predominantemente, por icterícia e caquexia (Barros 2016), porém muitas vezes os sinais são inespecíficos (Cullen \& Brown 2013). 0 diagnóstico é baseado nos exames laboratoriais como mensuração de atividades enzimáticas hepáticas e perfil hematológico, correlacionados com os sinais clínicos, porém o diagnóstico definitivo será através do exame histopatológico (Day 1995, Stonehewer 2006, German 2009).

Este trabalho tem como objetivos determinar a frequência de colângio-hepatite em gatos diagnosticados na Região Metropolitana de Porto Alegre, no período de janeiro de 2000 a julho de 2016, descrever seus aspectos anatomopatológicos e analisar a associação com as infecções por Escherichia coli, vírus da imunodeficiência felina (FIV) e vírus da leucemia felina (FeLV).

\section{MATERIAL E MÉTODOS}

Foram revisados os laudos de necropsias arquivados do Setor de Patologia Veterinária da Universidade Federal do Rio Grande do Sul (SPV-UFRGS) no período de janeiro de 2000 a julho de 2016, e selecionados para o estudo gatos diagnosticados com "colangite", "colângio-hepatite" e/ou "tríade felina". Foram considerados somente os casos em que a colângio-hepatite foi a causa da morte ou a razão para eutanásia do gato. Foram excluídos do trabalho os casos com marcada autólise, inflamação hepatobiliar discreta, neoplasmas, septicemias e hepatite sem o envolvimento biliar. Os dados referentes à identificação do felino, como raça, sexo e idade, e as lesões macroscópicas e microscópicas foram revisados e compilados. Dos casos selecionados, realizou-se a busca dos blocos de parafina arquivados para a confecção de lâminas histológicas com cortes de $3 \mu \mathrm{m}$, para posterior coloração pela técnica de hematoxilina e eosina (HE). Baseado nas alterações microscópicas, a colângio-hepatite foi classificada conforme Cullen \& Stlaker (2016). A graduação da inflamação foi baseada na densidade do infiltrado inflamatório e classificada em discreta, moderada e acentuada. A graduação da hiperplasia de ductos biliares, foi baseada nos achados descritos por Otte et al. (2014). Para a avaliação do grau de fibrose, cortes histológicos de fígado foram submetidos à coloração de tricrômico de Masson (TM) e posteriormente classificados em discreta, moderada e acentuada.

Secções de fígado e órgãos linfoides (linfonodo e/ou baço) foram submetidas à técnica de IHQ pelo método de polímero universal marcado com peroxidase (MACH 4 Universal HRP-Polymer - Biocare Medical), para os agentes Escherichia coli, FIV e FeLV. Controles positivos foram inseridos simultaneamente com as lâminas testadas e consistiam de casos testados previamente (Rolim et al. 2017). Para os controles negativos, utilizou-se tampão fosfato-salino (PBS) ao invés de anticorpo primário. Os protocolos IHQ realizados constam no Quadro 1.

No período de julho de 2015 a julho de 2016 foram coletadas amostras de bile e fígado de gatos com suspeita de doença hepática infecciosa para a realização do exame bacteriológico. Uma alçada (aproximadamente $10 \mu \mathrm{L}$ ) e uma gota (aproximadamente $30 \mu \mathrm{L}$ ) de fígado e bile, respectivamente, foram inoculadas em Ágar Mueller Hinton suplementado com 5\% de sangue ovino e em Ágar McConkey. As placas foram então incubadas em aerobiose a $37^{\circ} \mathrm{C}$ por até 72 horas.

\section{RESULTADOS}

No período de janeiro de 2000 a julho de 2016 o SPV-UFRGS realizou 1.915 necropsias de gatos, destes, 117 vieram a óbito ou foram submetidos à eutanásia devido a doenças hepatobiliares, sendo que 32 foram diagnosticados com colângio-hepatite, representando $1,7 \%$ do total de casos e $27,3 \%$ em relação às doenças hepatobiliares. A idade variou de quatro meses a 16 anos, com a idade média de 7,7 anos (mediana de seis anos). Em 84,4\% (27/32) dos casos afetou gatos sem raça definida (SRD), e os 15,6\% (5/32) restantes, gatos com raça. Em relação ao sexo, 56,2\% (18/32) dos gatos eram machos e 43,8\% (14/32) fêmeas. Do total dos gatos diagnosticados com colângio-hepatite, em $56,2 \%(18 / 32)$ apresentaram graus variados de pancreatite, $56,2 \%(18 / 32)$ enterite e em $46,9 \%$ (15/32) com lesões inflamatórias simultâneas no sistema hepatobiliar, pâncreas e intestino delgado. 


\section{Colângio-hepatite linfocítica}

Do total de 32 diagnósticos de colângio-hepatite, 22 casos foram classificados como CHL (68,7\%). Destes, 90,9\% (20/22) dos gatos eram SRD e 9,1\% (2/22) com raça (Himalaia e Persa). Em 50\% (11/22) dos casos acometeram fêmeas e a outra metade, machos. A idade variou de um ano a 16 anos, com idade média de 7,9 anos (mediana de 7,5 anos).

À necropsia, 54,5\% (12/22) dos gatos com CHL apresentaram escore corporal regular, 31,8\% (7/22) ruim, e em 13,6\% (3/22), identificou-se caquexia. Sinal de desidratação, analisado pela retração do globo ocular para dentro da sua órbita (enoftalmia), foi identificado em $68,2 \%(15 / 22)$ dos gatos. Em $50 \%(11 / 22)$ dos casos, as mucosas (conjuntival e oral) estavam ictéricas, $31,8 \%(7 / 22)$ pálidas, e 18,2\% (4/22) normocoradas. 0 tecido subcutâneo apresentou-se difusamente ictérico em $36,4 \%(8 / 22)$ dos casos. Em 59,1\% (13/22) dos casos foi identificado líquido translúcido a avermelhado na cavidade abdominal (ascite), 18,2\% (4/22) na cavidade torácica, e em 9,1\% (2/22), no saco pericárdio. Desvios portossistêmicos venosos extra-hepáticos ("shunts") foram relatados em 13,6\% (3/22) dos gatos. Quanto ao padrão macroscópico do fígado, $50 \%(11 / 22)$ encontraram-se aumentados de volume (Fig.1A), $22,7 \%(5 / 22)$ diminuídos, e em $27,3 \%(6 / 22)$, não houve alteração em relação ao tamanho do órgão. Quanto à coloração

\section{Quadro 1. Anticorpos e protocolos imuno-histoquímicos utilizados em casos de colângio-hepatite em gatos diagnosticados} no SPV-UFRGS

\begin{tabular}{|c|c|c|c|c|c|}
\hline Anticorpo & Código & Recuperação antigênica & Diluição & $\begin{array}{l}\text { Método de } \\
\text { detecção }\end{array}$ & Cromógeno \\
\hline anti-E. coli ${ }^{\mathrm{a} \text { Policlonal }}$ & 1001 & 5 min $(2 x) /$ micro-ondas, tampão citrato $\mathrm{pH} \mathrm{6,0}$ & $1: 200$ & $\mathrm{MACH}_{4}^{\mathrm{b}}$ & $\mathrm{AEC}^{\mathrm{c}}$ \\
\hline anti-FIV (p24 gag) ${ }^{\text {b Monoclonal }}$ & MCA 2278 & $40 \mathrm{~min} / 96^{\circ} \mathrm{C}, 0,01 \mathrm{M}$, tampão citrato $\mathrm{pH} 6,0$ & $1: 100$ & MACH4 & AEC \\
\hline anti-FeLV (gp70) ${ }^{\mathrm{b} \text { Monoclonal }}$ & MCA 1897 & 40 min $/ 96^{\circ} \mathrm{C}$, tampão Tris-EDTA pH 9,0 & $1: 500$ & MACH4 & AEC \\
\hline
\end{tabular}

Fontes de aquisição: ${ }^{\mathrm{a}}$ ViroStart, ${ }^{\mathrm{b}}$ Serotec, ${ }^{\mathrm{c}}$ Dako.

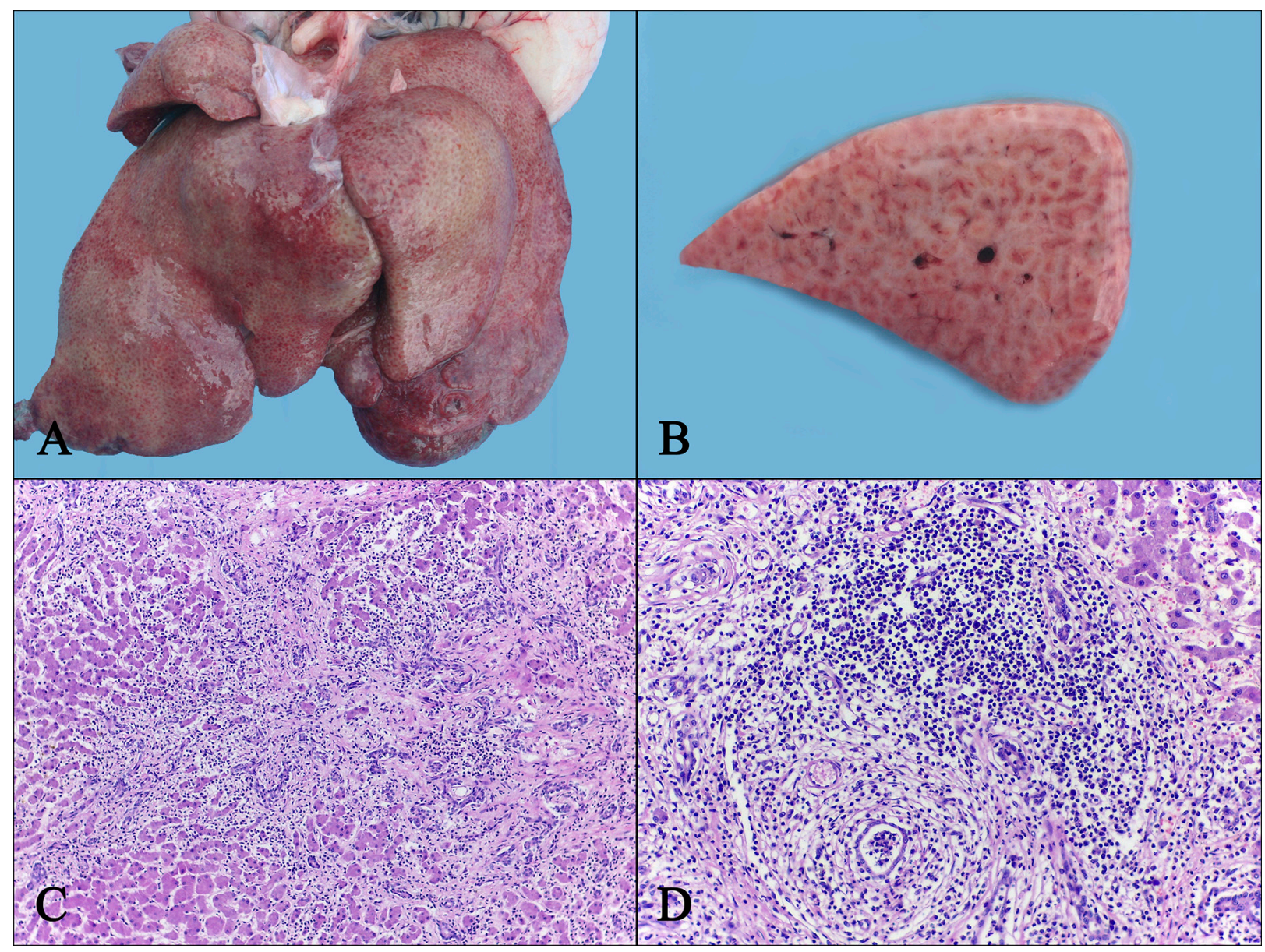

Fig.1. Aspectos macroscópicos e microscópicos de colângio-hepatite linfocítica em gatos. (A) Fígado discretamente aumentado de volume, pálido, com a superfície capsular levemente irregular e acentuação do padrão lobular. (B) Superfície de corte do fígado mostrando áreas claras circunjacentes às vermelhas. (C) Proliferação de tecido conjuntivo fibroso, de distribuição multifocal a coalescente associado com infiltrado inflamatório composto por linfócitos e plasmócitos, e discreta proliferação de ductos biliares. HE, obj.10x. (D) Infiltrado inflamatório composto predominantemente por linfócitos e plasmócitos, distribuídos no espaço porta e ao redor de ductos biliares proliferados e ocasionalmente dilatados e preenchidos por debris celulares, associado por discreta fibrose periportal. HE, obj.20x. 
do tecido hepático, 36,4\% (8/22) eram acastanhados, 31,8\% (7/22) alaranjados, 18,2\% (4/22) pálidos e 13,6\% (3/22) amarelos. Em 86,4\% (19/22) dos casos de CHL, os fígados encontraram-se firmes à palpação, e 13,6\% (3/22) friáveis. Acentuação do padrão lobular e superfície capsular com aspecto irregular foram identificadas em $68,2 \%(15 / 22)$ e $31,8 \%$ (7/22) dos casos, respectivamente. Em 22,7\% (5/22) dos casos apresentavam descrição da superfície de corte do tecido hepático, em que foram observadas áreas claras circunjacentes às vermelhas (Fig.1B). Áreas nodulares, esbranquiçadas a pardas, relativamente delimitadas de distribuição multifocal sobre a superfície capsular, que ao corte se aprofundavam no parênquima foram visualizadas em 63,6\% (14/22) e áreas vermelhas multifocais em 9,1\% (2/22) dos casos.

Nos casos de CHL, observou-se infiltrado inflamatório, composto predominantemente por linfócitos e plasmócitos, de distribuição multifocal, principalmente nas regiões periportais, com intensidade variando de moderada a acentuada. Em 54,5\% $(12 / 22)$ dos casos, o grau de proliferação de ductos biliares foi classificado como discreto, 27,3\% (6/22) moderado, e $18,2 \%$ (4/22) acentuado. Dilatação de ductos biliares, por vezes preenchidos por restos celulares foi visualizada em 40,9\% (9/22) dos casos de CHL. A proliferação de tecido conjuntivo fibroso foi identificada discretamente nas regiões periportais em 40,9\% (9/22), moderada em 36,4\% (8/22) e acentuada, com formação de pontes, em 22,7\% (5/22) dos casos (Fig.1C e D). Colestase intra-hepática foi visualizada de maneira discreta em 45,4\% (10/22) dos casos, moderada em $27,3 \%(6 / 22), 9,1 \%$ (2/22) acentuada, e em 18,2\% (4/22) não foi identificada esta alteração histológica.

Em 68,2\% (15/22) dos gatos com CHL apresentaram lesões histológicas de pancreatite, caracterizadas por infiltrado inflamatório, com predomínio de linfócitos e plasmócitos, distribuídos de maneira multifocal no interstício, perivascular e também nas regiões periductais. A intensidade da inflamação foi moderada em 45,4\% (10/22) dos casos, discreto em $13,6 \%(3 / 22)$ e acentuado em 9,1\% (2/22). Fibrose intersticial multifocal, associada à inflamação, foi verificada em discreta quantidade em 31,8\% (7/22) dos casos, moderada em $13,6 \%(3 / 22)$ e acentuada em $4,5 \%(1 / 22)$. Necrose de gordura peripancreática foi observada em $22,7 \%$ (5/22) dos casos. No intestino delgado, 59,1\% (13/22) dos gatos com CHL apresentaram discreto a moderado infiltrado inflamatório linfoplasmocitário, distribuído multifocalmente na submucosa e lâmina própria, em 9,1\% (2/22) dos casos o infiltrado inflamatório estendeu-se ao redor das glândulas de Brünner. Lesões microscópicas pancreáticas e entéricas concomitantes àquelas observadas no sistema hepatobiliar foram identificadas em 54,5\% (12/22) dos gatos com CHL.

Em relação à investigação de agentes infecciosos nos casos de CHL, através da IHQ, 27,3\% (6/22) dos casos apresentaram marcação para Escherichia coli no interior de ductos biliares (Fig.2A) e ocasionalmente entremeando os agregados inflamatórios. Quanto aos vírus, 40,9\% (9/22) dos casos apresentaram imunomarcação intracitoplasmática nos linfócitos dos órgãos linfoides para FeLV (Fig.2B), e em $22,7 \%$ (5/22) observaram-se discreta marcação multifocal nos agregados de células inflamatórias do tecido hepatobiliar (Fig.2C). Na avaliação IHQ anti-FIV, 68,2\% (15/22) dos gatos apresentaram imunorreação intracitoplasmática e intranuclear em linfócitos de órgão linfoide, destes, em 45,4\% (10/22) apresentaram ocasionais linfócitos imunomarcados no fígado de distribuição multifocal periportal (Fig.2D). Obteve-se marcação para ambos os vírus em 31,8\% (7/22) dos gatos com CHL.

0 exame bacteriológico foi realizado em 27,3\% (6/22) dos gatos com $\mathrm{CHL}$, onde se obteve crescimento bacteriano para os seguintes agentes: Klebsiella pneumoniae (2/6), crescimento misto para Enterococcus sp. e E. coli (1/6) e Salmonella sp. com $E$. coli (1/6). Sendo que, em 33,3\% (2/6) destes, não houve crescimento bacteriano significativo nas amostras de bile e/ou fragmento hepático.

\section{Colângio-hepatite neutrofílica}

Sete gatos foram diagnosticados com $\mathrm{CHN}$, perfazendo 21,9\% dos diagnósticos. Destes, 71,4\% (5/7) eram SRD e $28,6 \%$ (2/7) com raça definida (Siamês e Cornish Rex). Quanto ao sexo, 85,7\% (6/7) dos gatos com CHN eram machos, e $14,3 \%$ (1/7), fêmeas. A idade variou de quatro meses a cinco anos, com idade média de 5,8 anos (mediana de três anos).

Em 57,1\% (4/7) dos gatos com CHN estavam com estado nutricional ruim, 28,6\% (2/7) regular, e 14,3\% (1/7) com caquexia. Quanto à coloração das mucosas (conjuntival e oral), 71,4\% (5/7) encontraram-se pálidas, e em 28,6\% (2/7), levemente ictéricas. 0 tecido subcutâneo encontrou-se ictérico em 28,6\% (2/7) dos casos. Ascite e hidrotórax foram identificadas em 42,8\% (3/7) e 28,6\% (2/7) dos casos, respectivamente. 0 fígado de $71,4 \%$ (5/7) dos gatos diagnosticados com CHN apresentava discreto aumento de volume. Em relação à consistência, 42,8\% (3/7) eram friáveis à palpação e 14,3\% (1/7) levemente firmes. Quanto à coloração, 28,6\% (2/7) eram alaranjados, 28,6\% (2/7) vermelhos pálidos e 28,6\% (2/7) castanhos. Acentuação do padrão lobular foi identificada em 71,4\% (5/7) dos casos. Áreas multifocais vermelhas, assim como áreas multifocais arredondadas esbranquiçadas, foram identificadas em 28,6\% (2/7) dos casos, cada (Fig.3A). Material fibrilar levemente amarelado (fibrina) sobre a superfície capsular foi descrito em 14,3\% (1/7).

Os casos de CHN foram caracterizados por moderado a acentuado infiltrado inflamatório multifocal periportal, ocasionalmente envolvendo o epitélio ductal, composto, predominantemente, por neutrófilos, com ocasionais linfócitos e plasmócitos (Fig.3B). Quanto ao grau de proliferação de ductos biliares, 71,4\% (5/7) dos casos foi classificado como discreto, 14,3\% (1/7) moderado e 14,3\% (1/7) acentuado. Dilatação de ductos biliares, com o lúmen preenchido por restos celulares foi visualizada em 57,1\% (4/7) dos gatos (Fig.3C,D). Em relação ao grau de fibrose, identificada através do TM, $71,4 \%$ (5/7) dos casos apresentaram discreta proliferação de tecido conjuntivo fibroso periportal, 14,3\% (1/7) moderado e $14,3 \%$ (1/7) acentuado. Em 57,1\% (4/7) dos casos observou colestase intra-hepática moderada.

Pancreatite foi observada em 28,6\% (2/7) dos gatos com CHN, estes apresentaram moderado infiltrado inflamatório intersticial multifocal, composto predominantemente por linfócitos e plasmócitos, com ocasionais neutrófilos, e em $14,3 \%$ (1/7) observou discreta fibrose intersticial, associada com moderada necrose da gordura peripancreática. Em 57,1\% (4/7) dos gatos apresentavam enterite, e exibiram infiltrado inflamatório discreto a moderado, composto por linfócitos e plasmócitos, distribuídos multifocalmente na submucosa e 


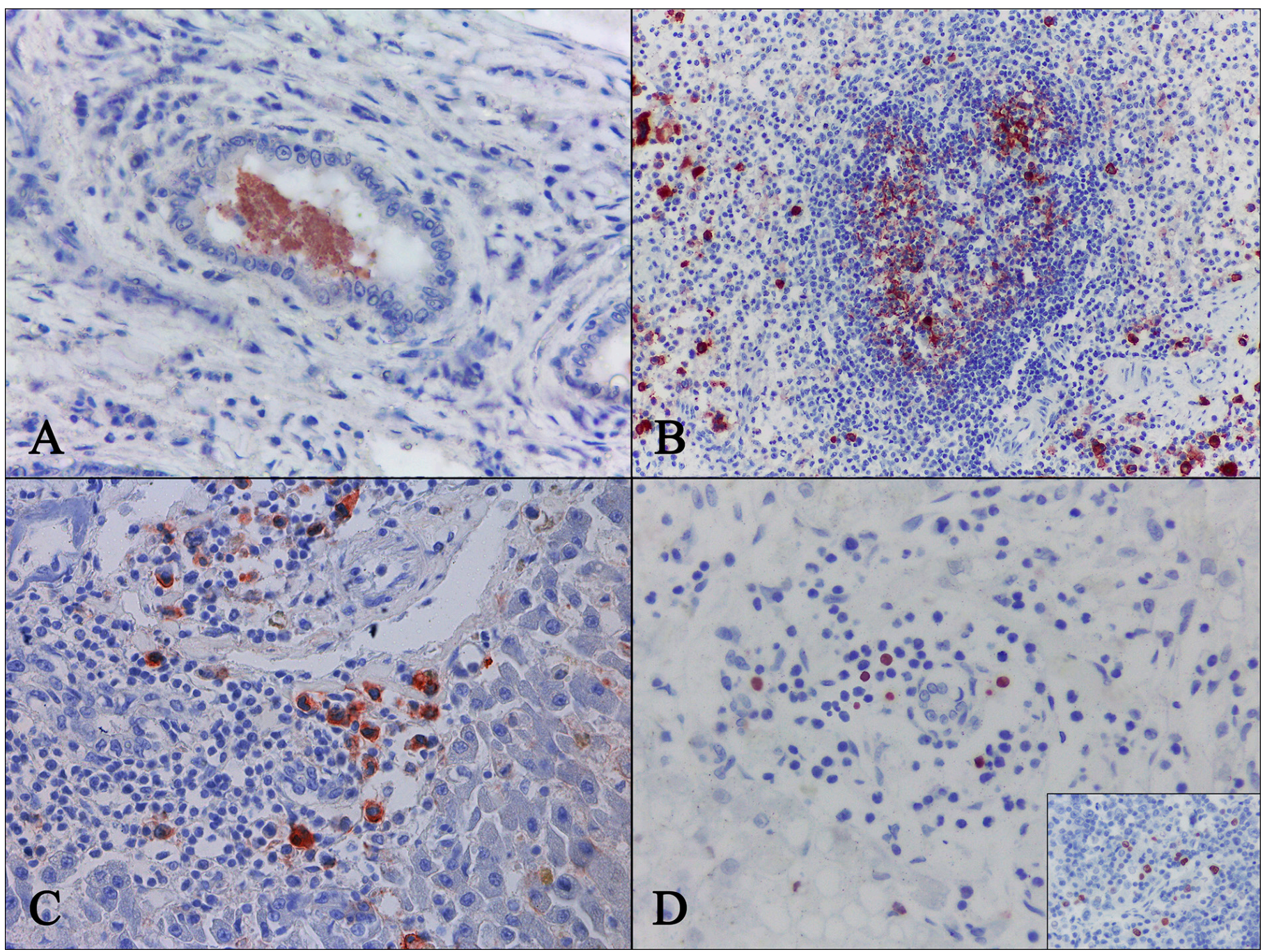

Fig.2. Investigação de agentes infecciosos nos gatos diagnosticados com colângio-hepatite. (A) Marcação anti-E. coli no interior de um ducto biliar em um caso de colângio-hepatite linfocítica (CHL). IHQ, AEC, obj.40x. (B) Marcação multifocal e intracitoplasmática anti-FeLV no baço de um gato com CHL. IHQ, AEC, obj.20x. (C) Imunorreação anti-FeLV multifocal no citoplasma de plasmócitos e macrófagos, localizados no espaço porta. IHQ AEC, obj.40x. (D) Marcação anti-FIV em ocasionais linfócitos localizados ao redor de um ducto biliar. IHQ, AEC, obj.40x. Detalhe: imuno-histoquímica positiva em linfócitos de um linfonodo de um gato com CHL. IHQ, AEC, obj.40x.

lâmina própria. Nestes casos, pancreatite concomitante com a enterite foi identificada em $28,6 \%$ (2/7) dos gatos com CHN.

Quanto à identificação de agentes infecciosos, 28,6\% (2/7) dos gatos apresentaram marcação para E. coli, visualizada através da IHQ, multifocalmente no interior de ductos biliares e em ocasionais agregados inflamatórios. Em relação ao FeLV, em 57,1\% (4/7) dos casos observaram imunomarcação intracitoplasmática nos órgãos linfoides, não identificando marcação no tecido hepatobiliar para este agente. Imunorreatividade para FIV foi identificada em 85,7\% (6/7) dos gatos com CHN, destes, 50\% (3/6) apresentaram, ainda, marcação intracitoplasmática e intranuclear em raras células inflamatórias no fígado. A associação entre FeLV e FIV foi identificada em 42,8\% (3/7) dos casos da forma neutrofílica.

Em 14,3\% (1/7) dos casos de CHN foi coletada amostra de bile e fígado para a realização do exame bacteriológico, onde constatou crescimento misto de Enterococcus sp. e E. coli.

\section{Colângio-hepatite esclerosante}

Três gatos foram diagnosticados com CHE ( $9,4 \%$ dos casos). Destes, 66,7\% (2/3) eram fêmeas e SRD, e 33,3\% (1/3), macho da raça Persa. A idade variou de quatro a 14 anos, com média de nove anos (mediana de 10 anos).

À necropsia, 66,7\% (2/3) dos gatos com CHE apresentaram estado corporal ruim, e em 33,3\% (1/3), caquexia. Mucosas conjuntivais e oral, e tecido subcutâneo de coloração amarela, líquido translúcido na cavidade abdominal e desvios portossistêmicos venosos extra-hepáticos ("shunts") foram observados em todos os casos. Em relação ao padrão macroscópico do fígado, $66,7 \%$ (2/3) dos casos encontraram-se diminuídos de tamanho, castanhos pálidos, firmes à palpação, com a superfície capsular irregular, com acentuação do padrão lobular e áreas multifocais a coalescentes esbranquiçadas (Fig.4A). Em 33,3\% (1/3) dos casos, não houve alteração quanto ao tamanho do órgão, onde observou ainda, consistência firme 


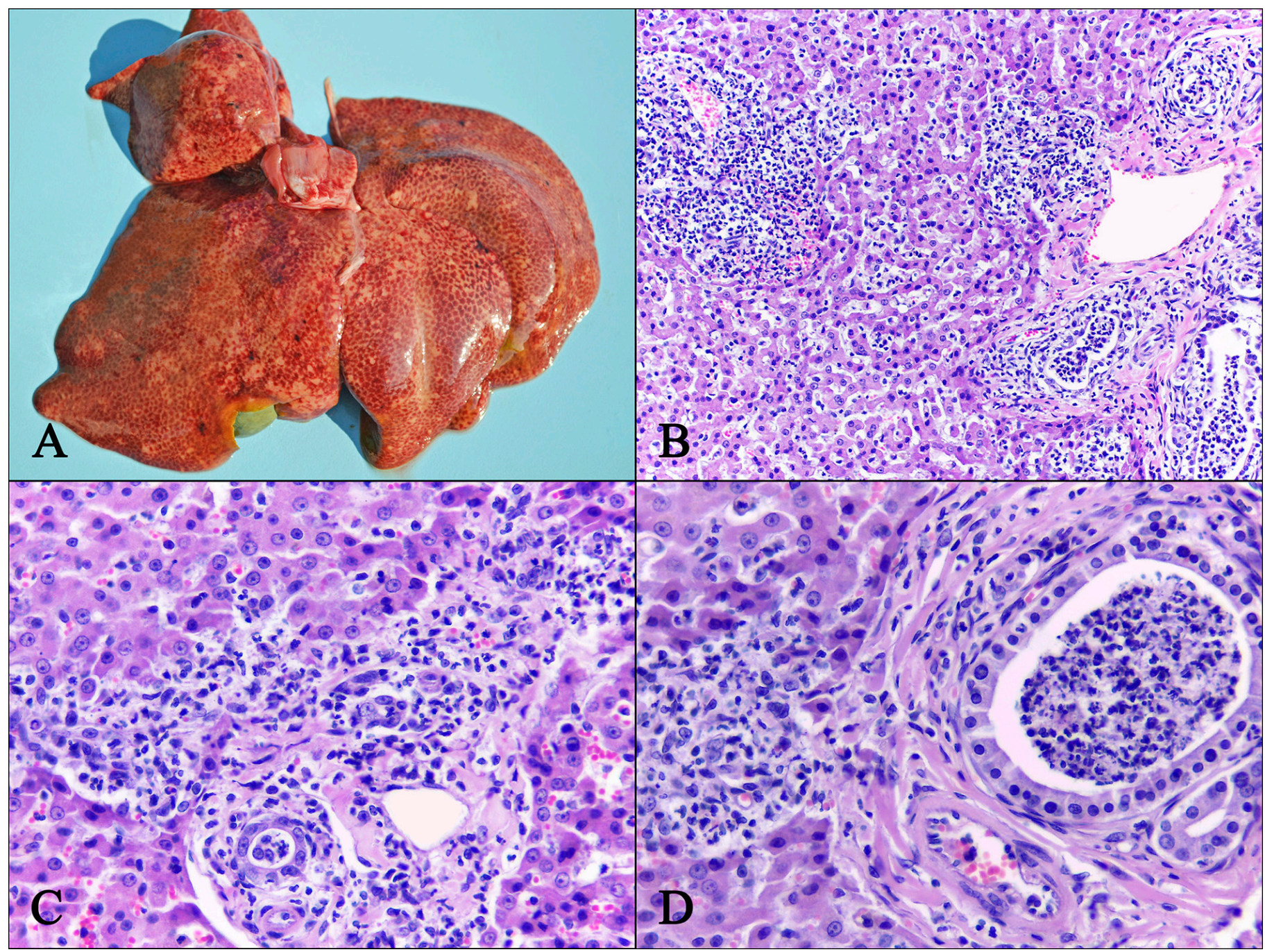

Fig.3. Achados macroscópicos e microscópicos da colângio-hepatite neutrofílica em gatos. (A) Fígado levemente aumentado de volume, alaranjado, com acentuação do padrão lobular, múltiplas áreas esbranquiçadas e vermelhas na superfície capsular. (B) Infiltrado inflamatório composto por neutrófilos no lúmen e no epitélio dos ductos biliares, estendendo-se nas regiões periportais e de distribuição multifocal. HE, obj.10x. (C) Infiltrado inflamatório, composto predominantemente por neutrófilos, com ocasionais linfócitos e plasmócitos, localizados na região periportal, lúmen e epitélio ductal. HE, obj.40x. (D) Infiltrado neutrofílico e debris celulares no interior de um ducto biliar, e agregado neutrofílico no parênquima hepático circunjacente. HE, obj.40x.

e coloração castanha a levemente amarelada, contendo áreas vermelhas multifocais na superfície capsular, intercaladas com pequenas áreas nodulares esbranquiçadas. Dilatação nos ductos biliares e na vesícula foi observada em $66,7 \%(2 / 3)$, ainda, ao corte observaram ductos biliares intra-hepáticos evidentes, espessados, calibrosos e amarelados (Fig.4B).

Os três casos apresentaram lesões microscópicas, caracterizadas por substituição do parênquima hepático normal por acentuada proliferação de tecido conjuntivo fibroso (evidenciado pela coloração de Tricrômico de Masson), de distribuição multifocal a coalescente, por vezes com formação de pontes, associada com moderado infiltrado inflamatório multifocal periportal, composto principalmente por linfócitos e plasmócitos, e com proliferação de ductos biliares em grande quantidade, por vezes apresentavam-se dilatados e ocasionalmente preenchidos por restos celulares (Fig.4C,D). A vesícula biliar foi coletada e analisada em $66,7 \%(2 / 3)$ dos casos, onde observou moderada hiperplasia do epitélio de revestimento da mucosa, com a formação de discretas projeções digitiformes que se orientavam para a luz do órgão.

Alterações microscópicas no pâncreas e no intestino delgado estavam presentes em 33,3\% (1/3) dos casos de CHE, e se caracterizam por moderado infiltrado inflamatório de linfócitos e plasmócitos multifocalmente no interstício (pâncreas), submucosa, lâmina própria e ocasionalmente ao redor de glândulas de Brünner (intestino delgado).

Quanto aos resultados da IHQ, 33,3\% (1/3) dos casos apresentaram marcação para E. coli associada à inflamação. Em 100\% (3/3) foi positivo para FeLV com marcação em órgão linfoide, e 66,7\% (2/3), imunorreação discreta em agregados inflamatórios no sistema hepatobiliar. Em relação à IHQ anti-FIV, 33,3\% (1/3) dos gatos diagnosticados com CHE apresentaram imunomarcação intracitoplasmática e intranuclear em tecido linfoide, não identificando marcação 


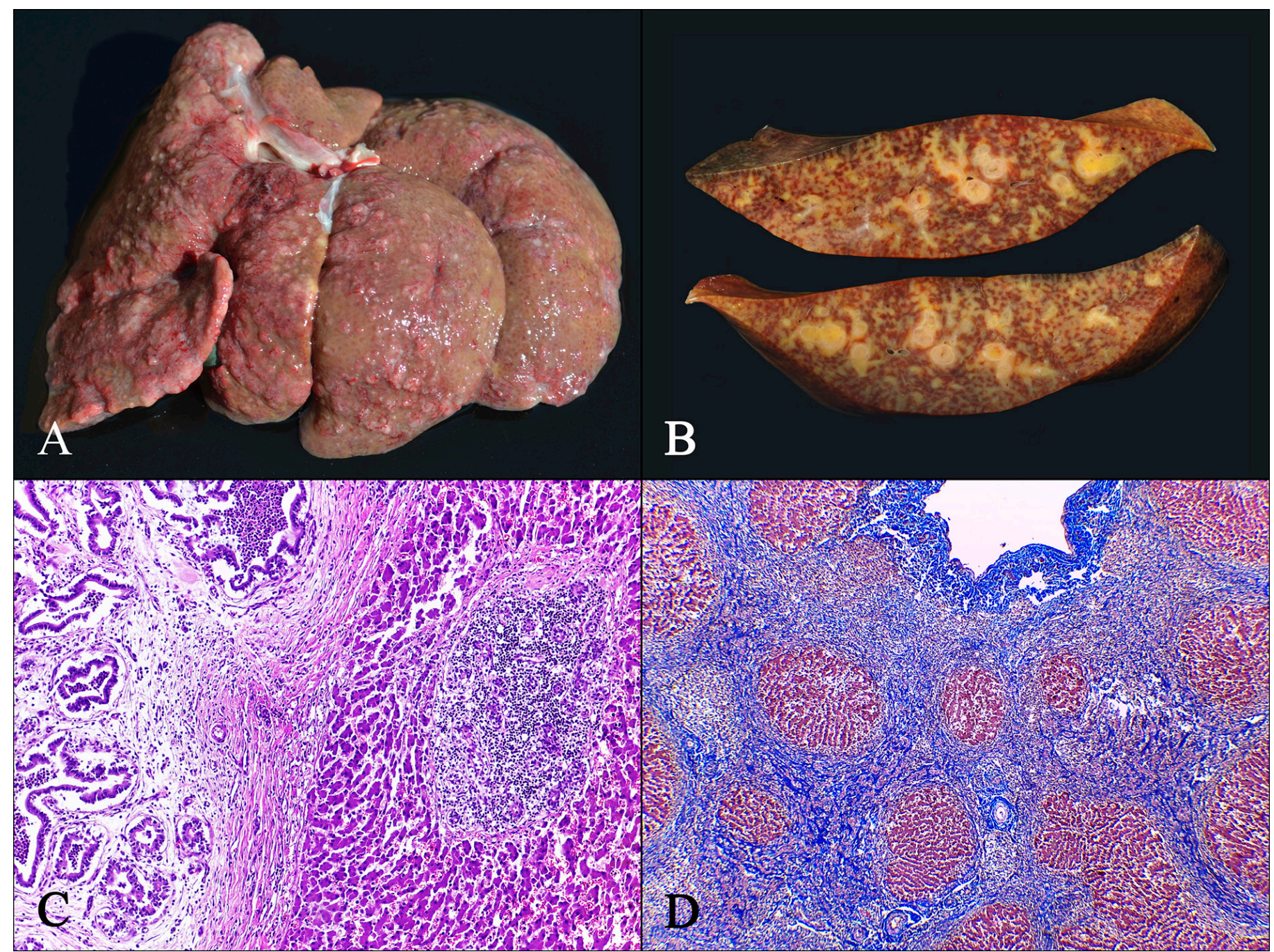

Fig.4. Aspectos macroscópicos e microscópicos de colângio-hepatite esclerosante em gatos. (A) Fígado diminuído de volume, com superfície capsular irregular, observando-se múltiplas áreas nodulares e esbranquiçadas. (B) Superfície de corte do tecido hepático, mostrando ductos biliares intra-hepáticos espessados, calibrosos e amarelados, de distribuição multifocal. (C) Proliferação de tecido conjuntivo fibroso, proliferação de ductos biliares, que se encontram dilatados e preenchidos por debris celulares, além de infiltrado inflamatório de linfócitos e plasmócitos. HE, obj.10x. (D) Acentuada fibrose multifocal a coalescente, com formação de pontes. Tricrômico de Masson, obj.5x.

no fígado. A presença dos dois agentes virais foi verificada em $33,3 \%(1 / 3)$ dos casos.

Em relação aos resultados do exame bacteriológico, em $33,3 \%(1 / 3)$ dos casos de CHE se realizou a coleta de bile e fígado, onde verificou crescimento de Citrobacter sp.

\section{DISCUSSÃO}

No presente trabalho, a frequência de colângio-hepatite em gatos foi de $1,7 \%$ do total e $27,3 \%$ em relação às doenças hepatobiliares. Em uma pesquisa semelhante, a frequência foi de $0,86 \%$ (Clark et al. 2011). Apesar da baixa frequência, a colângio-hepatite é a segunda doença hepática mais comum em gatos (Zawie \& Garvey 1984, Cullen \& Brown 2013).

Quanto à classificação, no presente estudo a CHL foi a mais frequente, representando $68,7 \%$ dos casos, seguida pela CHN e CHE, com 21,9\% e 9,4\%, respectivamente. Gagne et al. (1999) e Warren et al. (2011) descrevem que a forma linfocítica é a mais frequente, porém, diversos pesquisadores relatam que a CHN é a forma mais comum em gatos (Van den Ingh et al. 2006, Morgan et al. 2009, Clark et al. 2011, Hirose et al. 2014). O número reduzido de casos de CHE tem sido atribuído ao fato de que a maioria dos gatos morre espontaneamente ou é submetido à eutanásia antes que a doença progrida para a sua fase terminal (Day 1995).

De uma maneira geral, gatos SRD foram os mais afetados no presente estudo, assim como descrito por Clark et al. (2011) e Marolf et al. (2012). Este dado é atribuído possivelmente ao fato de estes animais representarem a maioria da população felina encaminhadas para o SPV-UFRGS. Diversos pesquisadores relatam que não há predisposição racial em gatos com colângio-hepatite (Morgan et al. 2009, Marolf et al. 2012), porém, na forma linfocítica, a raça Persa é a mais acometida (Lucke \& Davies 1984, German 2009). Gatos com CHL e CHE 
não apresentaram predisposição sexual, concordando com diversas pesquisas (Lucke \& Davies 1984, Clark et al. 2011, Marolf et al. 2012), porém, na forma neutrofílica, os machos foram mais frequentes, corroborando com diversos estudos (Gagne et al. 1999, Morgan et al. 2009, Hirose et al. 2014).

A idade média dos gatos com colângio-hepatite foi de 7,7 anos (mediana de seis anos). Em pesquisas semelhantes, a idade média variou de nove a 11,2 anos (Gagne et al. 1999, Morgan et al. 2009, Clark et al. 2011, Marolf et al. 2012). Gatos com apresentação da forma neutrofílica apresentaram idade média inferior (5,8 anos) quando comparados com gatos diagnosticados com CHL e CHE $(7,9$ e nove anos, respectivamente). Este dado está de acordo com o descrito na literatura (Gagne et al. 1999, Clark et al. 2011, Cullen \& Brown 2013), entretanto, apesar da CHN acometer gatos de qualquer idade, alguns pesquisadores descrevem que esta forma é mais comum em idosos (Shaker et al. 1991, Center 2009, German 2009, Hirose et al. 2014).

Mau estado corporal, desidratação, mucosas ictéricas, efusões abdominais e torácicas, foram alterações macroscópicas frequentes, identificadas, principalmente, nos casos mais crônicos, como na CHL e CHE. Desvios portossistêmicos venosos extra-hepáticos adquiridos foram identificados 13,6\% dos casos de CHL e em todos os casos da forma esclerosante. Estas alterações são frequentes em casos de doenças hepáticas em gatos e são descritas por diversos pesquisadores (Day 1998, Ilha et al. 2004, Marolf et al. 2012, Barros 2016). Gatos diagnosticados com CHN apresentavam, predominantemente, estado corporal ruim, e variação no grau de icterícia e de ascite, assim como descrito na literatura (Hirsch \& Doige 1983, Day 1995, Clark et al. 2011). Sugere-se que ascite e a formação de desvios portossistêmicos, ocorreram em consequência da hipertensão portal em decorrência de doença hepática crônica. A hipoproteinemia, em função da insuficiência hepática, também está envolvida na formação das efusões cavitárias (Ilha et al. 2004). A icterícia deve-se a colestase, que ocorre pelo impedimento do fluxo dentro dos canalículos, e como consequência de lesão hepática difusa (icterícia hepática) (Barros 2016).

Os fígados apresentaram variação na sua apresentação, porém, a maioria dos casos de CHL, observou fígado aumentado de tamanho, alaranjado a acastanhado, firme e com áreas esbranquiçadas multifocais na superfície capsular, que se aprofundavam no parênquima. Dados semelhantes foram descritos por diversos pesquisadores (Lucke \& Davies 1984, Barros 2016). Hepatomegalia é um achado comum na colângio-hepatite, provavelmente decorrente do infiltrado inflamatório e é descrita por Prasse et al. (1982), Sherding (2000) e Fragkou et al. (2016). 0 aspecto macroscópico do fígado dos casos de CHE corrobora com o descrito por Ilha et al. (2004), sendo caracterizado por diminuição do volume do órgão, firme à palpação e com a superfície capsular irregular, provavelmente causadas pela substituição do parênquima hepático por proliferação de tecido conjuntivo.

ACHL caracterizou-se por múltiplos agregados de linfócitos nos espaços portas, com graus variáveis de proliferação de ductos biliares e fibrose. Na CHN observou infiltrado neutrofílico nas regiões periportais, envolvendo também o epitélio e/ou lúmen dos ductos biliares. Em alguns casos, evidenciou infiltrado inflamatório misto, proliferação de ductos biliares e fibrose periportal. Nos casos de CHE, observou acentuada proliferação de tecido conjuntivo fibroso, hiperplasia e dilatação de ductos biliares, além de infiltrado inflamatório predominantemente linfoplasmocitário. As alterações microscópicas encontradas nas diferentes classificações das colângio-hepatites são descritas na literatura (Day 1995, Ilha et al. 2004, Van den Ingh et al. 2006, Center 2009, Clark et al. 2011, Cullen \& Brown 2013, Cullen \& Stlaker 2016). Barros (2016) descreve que a fibrose está associada à inflamação crônica da região portal e geralmente é observada em gatos com colângio-hepatite. A hiperplasia de ductos biliares é uma resposta inespecífica a vários tipos de lesão hepática, principalmente após doenças que causam obstrução física do fluxo normal da bile.

Enterite e pancreatite foram identificadas concomitantemente com a colângio-hepatite. Estes dados estão de acordo com diversas pesquisas semelhantes, onde a frequência de enterite em gatos com colângio-hepatite variou de $34 \%$ a 83,3\% (Weiss et al. 1996, Swift et al. 2000, Clark et al. 2011, Twedt et al. 2014, Fragkou et al. 2016) e de pancreatite em $50 \%$ a 65,2\% (Weiss et al. 1996, Swift et al. 2000, Clark et al. 2011, Twedt et al. 2014).

A formação de tríade também foi identificada. Em outras pesquisas, a frequência dessa condição variou de $29,6 \%$ a 55,5\% (Weiss et al. 1996, Swift et al. 2000, Clark et al. 2011, Twedt et al. 2014, Fragkou et al. 2016). Tríade foi observada em todas as classificações histológicas da colângio-hepatite, como descrita por Clark et al. (2011). Uma explicação para o maior desenvolvimento de tríade nos gatos está relacionada com as características anatômicas dessa espécie, representadas pela fusão do ducto biliar comum com o ducto pancreático maior antes de entrarem no duodeno, o que predispõe a infecção bacteriana ascendente (Cullen \& Brown 2013, Cullen \& Stlaker 2016).

Infecções virais concomitantes com colângio-hepatite em gatos são raras (Lucke \& Davies 1984, Nakayama et al. 1992, Brain et al. 2006, Center 2009). Callanan et al. (1992) descreveram o desenvolvimento de colângio-hepatite, com marcada hiperplasia de ductos biliares, após infecção experimental por FIV. Uma possível explicação para a alta frequência de gatos com colângio-hepatite e infectados pelos retrovírus, é a acentuada linfopenia causada por estes, em decorrência da diminuição nos níveis de linfócitos $\mathrm{T}$ auxiliares (CD4+), nos quais tem um papel importante no desenvolvimento da resposta (Fighera \& Graça 2016). Isso leva ao comprometimento o sistema imunológico do gato, o que causa infecções secundárias (Hartmann 2012). Uma possível explicação para a maior frequência de gatos com CHN infectados pelos retrovírus, é que $85,7 \%$ dos felinos diagnosticados nessa classificação são machos e jovens, nos quais são mais suscetíveis às infecções por agentes virais imunossupressores devido ao comportamento errante e agressivo destes, pois, a transmissão dos retrovírus nessa espécie ocorre, principalmente, através da saliva, por meio de mordeduras em brigas (Fighera \& Graça 2016). Deve-se considerar que esta maior frequência de gatos FIV e/ou FeLV positivos neste estudo, pode estar relacionada a população de felinos atendidos na Região Metropolitana de Porto Alegre, que provavelmente apresenta uma alta prevalência de infecções por retrovírus, sem que isto esteja relacionado com a colângio-hepatite. Em humanos, existe uma colangiopatia infecciosa em pacientes imunodeprimidos, associada ao vírus da imunodeficiência humana (HIV) e de etiologia multifatorial, 
sendo a principal causa, as infecções secundárias (Flores \& Osvaldt 2005).

Escherichia coli foi identificada através da IHQ em 28,1\% dos gatos, sendo que na $\mathrm{CHL}, 27,3 \%$ dos casos foram positivos, na CHN com 28,6\% e CHE com 33,3\%. E. coli, Enterococcus sp., Klebsiella pneumoniae, além de outras bactérias comensais intestinais, foram os principais isolados no exame bacteriológico. Estes dados corroboram com os descritos na literatura (Brain etal. 2006, Wagner et al. 2007). Diversos pesquisadores sugerem o envolvimento da E. coli em casos de colângio-hepatite de gatos (Kaufman 1994, Wagner et al. 2007, Clark et al. 2011, Otte et al. 2012, Cullen \& Stlaker 2016), porém, a visualização de bactérias no lúmen dos ductos biliares em cortes histológicos é descrita em raros casos (Lapointe et al. 2000, Ilha et al. 2004). Em dois casos, não houve crescimento bacteriano significativo nas amostras. A antibioticoterapia pode ser apontada como uma provável causa do insucesso no isolamento de microorganismos nestes gatos. Sugere-se ainda, que pode haver ausência do agente infeccioso no sistema hepatobiliar do gato no momento da necropsia, por causa da cronicidade da lesão hepática e também, pelo avançado estágio da doença clínica (Ilha et al. 2004).

A visualização de E. coli, através da IHQ no sistema hepatobiliar de gatos diagnosticados com colângio-hepatite associados à inflamação, sugere-se que a doença se desenvolveu por infecção bacteriana ascendente. Micro-organismos pertencentes à flora comensal do trato gastrointestinal seriam capazes de invadir a árvore biliar, provocando a inflamação. As formas linfocítica e esclerosante podem ser estágios evolutivos da doença, quando o agente infeccioso já teria sido destruído, mas mecanismos imunológicos perpetuariam a agressão ao sistema hepatobiliar (Zawie \& Garvey 1984, Center \& Rowland 1994, Day 1995, Barros 2016). Diversos pesquisadores fornecem evidências adicionais de uma patogênese imunomediada na CHL, de maneira semelhante à colangite esclerosante primária e cirrose biliar primária em humanos (Day 1998, Cullen \& Brown 2013). Otte et al. (2012) sugerem que a presença de bactérias na bile de gatos é secundária e não é a causa da CHL, pois a invasão bacteriana retrógrada pelo ducto biliar comum pode ser facilitada por dilatações e peristaltismo reduzido devido à inflamação crônica dos canais biliares.

\section{CONCLUSÕES}

A colângio-hepatite linfocítica foi a classificação histológica mais frequente, afetando principalmente gatos idosos. A forma neutrofílica foi a segunda mais frequente e acometeu predominantemente jovens. A colângio-hepatite esclerosante foi pouco observada em gatos.

Mau estado corporal, desidratação, mucosas ictéricas, efusões abdominais e torácicas, foram os principais achados macroscópicos nos gatos diagnosticados com as diferentes classificações de colângio-hepatite. Os fígados apresentaram variação na sua apresentação macroscópica, sendo que, nas formas crônicas da colângio-hepatite, observou frequentemente fígado firme, castanho, de superfície irregular e com acentuação do padrão lobular. Lesões no pâncreas e intestino foram comumente encontradas em gatos com colângio-hepatite.

A maioria dos gatos do presente estudo apresentava infecção por vírus da imunodeficiência felina e/ou vírus da leucemia felina concomitantemente com a colângio-hepatite.
Bactérias comensais do trato gastro intestinal como Escherichia coli, Enterococcus sp. e Klebsiella pneumoniae foram os principais micro-organismos isolados no exame bacteriológico.

A visualização de E. coli através da IHQ nas diferentes classificações de colângio-hepatite, sugere causa infecciosa nos casos analisados.

A colângio-hepatite deve ser incluída no diagnóstico diferencial de gatos com sinais clínicos de insuficiência hepática.

\section{REFERÊNCIAS}

Barros C.S.L. 2016. Fígado, vias biliares e pâncreas exócrino, p.222-265. In: Santos R.L. \& Alessi A.C. (Eds), Patologia Veterinária. 2ª ed. Roca, Rio de Janeiro. 856p.

Brain P.H., Barrs V.R., Martin P., Baral R., White J.D. \& Beatty J.A. 2006. Feline cholecystitis and acute neutrophilic cholangitis: clinical findings, bacterial isolates and response to treatment in six cases. J. Fel. Med. Surg. 8(2):91103. http://dx.doi.org/10.1016/j.jfms.2005.09.001. PMid:16278090.

Callanan J.J., Thompson H., Toth S.R., Lawrence C.E., Willett B. \& Jarrett O. 1992. Clinical and pathological findings in feline immunodeficiency virus experimental infection. Vet. Immunol. Immunopathol. 35(1/2):3-13. http:// dx.doi.org/10.1016/0165-2427(92)90116-8. PMid:1337400.

Center S.A. 2009. Diseases of the gallbladder and biliary tree. Vet. Clin. N. Am., Small Anim. Pract. 39(3):543-598. http://dx.doi.org/10.1016/j. cvsm.2009.01.004. PMid:19524793.

Center S.A. \& Rowland P.H. 1994. The cholangitis/cholangiohepatitis complex in the cat. Proceedings 12th Annual Am. College Vet. Intern. Med. Forum, California, p.766-771.

Clark J.E.C., Haddad J.L., Brown D.C., Morgan M.J., Van Winkle T.J. \& Rondeau M.P. 2011. Feline cholangitis: a necropsy study of 44 cats (1986 e 2008). J. Fel. Med. Surg. 13(8):570-576. http://dx.doi.org/10.1016/j.jfms.2011.05.002.

Cullen J.M. \& Brown D.L. 2013. Sistema hepatobiliar e pâncreas exócrino, p.453-454. In: McGavin M.D. \& Donald J.F (Eds), Bases da Patologia em Veterinária. 5a ed. Elsevier, Rio de Janeiro. 1324p.

Cullen J.M. \& Stlaker M.J. 2016. Liver and biliary system, p.307-308. In: Maxie M.G. (Ed.), Jubb, Kennedy and Palmer's Pathology of Domestic Animals. Vol.2. 6th ed. Elsevier, St Louis. 654p. http://dx.doi.org/10.1016/B9780-7020-5318-4.00008-5.

Day D.G. 1995. Feline cholangiohepatitis complex. Vet. Clin. N. Am., Small Anim. Pract. 25(2):375-385. http://dx.doi.org/10.1016/S0195-5616(95)500324. PMid:7785169.

Day M.J. 1998. Imunohistochemical characterization of the lesions of the feline progressive lymphocytic cholangitis/cholangiohepatitis. J. Comp. Pathol. 119(2):135-147. http://dx.doi.org/10.1016/S0021-9975(98)80058-3. PMid:9749358.

Fighera R.A. \& Graça D.L. 2016. Sistema hematopoiético, p.311-405. In: Santos R.L. \& Alessi A.C. (Eds), Patologia Veterinária. $2^{\underline{a}}$ ed. Roca, Rio de Janeiro. 856p.

Flores C. \& Osvaldt A.B. 2005. Colangite infecciosa, p.320-324. In: Rohde L. \& Osvaldt A.B. (Eds), Rotinas em Cirurgia Digestiva. Artmed, Porto Alegre. 519p.

Fragkou F.C., Adamama-Moraitou K.K., Poutahidis T., Prassinos N.N., KritsepiKonstantinou M., Xenoulis P.G., Steiner J.M., Lidbury J.A., Suchodolski J.S. \& Rallis T.S. 2016. Prevalence and clinicopathological features of triaditis in a prospective case series of symptomatic and asymptomatic cats. J. Vet. Intern. Med. 30(4):1031-1045. http://dx.doi.org/10.1111/jvim.14356. PMid:27296565.

Gagne J.M., Armstrong P.J., Weiss D.J., Lund E.M., Feeney D.A. \& King V.L. 1999. Clinical features of inflammatory liver disease in cats: 41 cases (1983-1993). J. Am. Vet. Med. Assoc. 214(4):513-516. PMid:10029853.

German A. 2009. How I treat feline cholangiohepatitis. Vet. Focus 19:41-46. 
Hartmann K. 2012. Clinical aspects of feline retroviruses: a review. Viruses 4(11):2684-2710. http://dx.doi.org/10.3390/v4112684. PMid:23202500.

Hirose N., Uchida K., Kanemoto H., Ohno K., Chambers J.K. \& Nakayama H. 2014. A retrospective histopathological survey on canine and feline liver diseases at the University of Tokyo between 2006 and 2012. J. Vet. Med. Sci. 76(7):1015-1020. http://dx.doi.org/10.1292/jvms.14-0083. PMid:24717415.

Hirsch V.M. \& Doige C.E. 1983. Suppurative cholangitis in cats. J. Am. Vet. Med. Assoc. 182(11):1223-1226. PMid:6863138.

Ilha M.R.S., Loretti A.P., Barros C.S.L., Mazzanti A. \& Breitsameter I. 2004. Cirrose biliar em felinos associada à ectasia do ducto cístico e desvios portossistêmicos extra-hepáticos. Ciência Rural 34(4):1147-1153. http:// dx.doi.org/10.1590/S0103-84782004000400028.

Kaufman A.C. 1994. Infectious causes of feline hepatobiliary disease. Vet. Med. 89:869-873.

Lapointe J.M., Higgins R., Barrette N. \& Milette S. 2000. Enterococcus hirae enteropathy with ascending cholangitis and pancreatitis in a kitten. Vet. Pathol. 37(3):282-284. http://dx.doi.org/10.1354/vp.37-3-282. PMid:10810996.

Lucke V.M. \& Davies J.D. 1984. Progressive lymphocytic cholangitis in the cat. J. Small Anim. Pract. 25(5):249-260.http://dx.doi.org/10.1111/j.1748-5827.1984. tb03388.x.

Marolf A.J., Leach L., Gibbons D.S., Bachand A. \& Twedt D. 2012. Ultrasonographic findings of feline cholangitis. J. Am. Anim. Hosp. Assoc. 48(1):36-42. http:// dx.doi.org/10.5326/JAAHA-MS-5671. PMid:22186719.

Morgan M., Rondeau M., Rankin S., Shofer F., Berent A., Van Winkle T. \& Washabau R. 2009. A survey of feline inflammatory hepatobiliary disease using the WSAVA classification system. J. Vet. Intern. Med. 22:806.

Nakayama H., Uchida K., Lee S.K., Uetsuka K., Hasegawa A. \& Goto N. 1992. Three cases of feline sclerosing lymphocytic cholangitis. J. Vet. Med. Sci. 54(4):769-771. http://dx.doi.org/10.1292/jvms.54.769. PMid:1391190.

Otte C.M.A., Gutiérrez O.O., Favier R.P., Rothuizen J. \& Penning L.C. 2012. Detection of bacterial DNA in bile of cats with lymphocytic cholangitis. Vet. Microbiol. 156(1/2):217-221. http://dx.doi.org/10.1016/j. vetmic.2011.10.023. PMid:22101090.

Otte C.M.A., Rothuizen J., Favier R.P., Penning L.C. \& Vreman S. 2014. A morphological and immunohistochemical study of the effects of prednisolone or ursodeoxycholic acid on liver histology in feline lymphocytic cholangitis. J. Feline Med. Surg. 16(10):796-804. http://dx.doi. org/10.1177/1098612X14520811. PMid:24496321.
Prasse K.W., Mahaffey E.A., DeNovo R. \& Cornelius L. 1982. Chronic lymphocytic cholangitis in three cats. Vet. Pathol. 19(2):99-108. http:// dx.doi.org/10.1177/030098588201900201. PMid:7072097.

Rolim V.M., Pavarini S.P., Campos F.D., Pignone V., Faraco C., Muccillo M.S., Roehe P.M., da Costa F.V. \& Driemeier D. 2017. Clinical, pathological, immunohistochemical and molecular characterization of feline chronic gingivostomatitis. J. Fel. Med. Surg. 19(4):403-409. PMid:26858258.

Shaker E.H., Zawie D.A., Garvey M.S. \& Gilbertson S.R. 1991. Suppurative cholangiohepatitis in a cat. J. Am. Anim. Hosp. Assoc. 27:148-150.

Sherding R.G. 2000. Feline jaundice. J. Feline Med. Surg. 2(3):165-169. http:// dx.doi.org/10.1053/jfms.2000.0088. PMid:11716613.

Stonehewer J. 2006. Fígado e pâncreas, p.358-372. In: Chandler E.A. \& Gaskell R.M. (Eds), Clínica e Terapêutica em Felinos. 3ae ed. Roca, São Paulo. 632p.

Swift N.C., Marks S.L., MacLachlan N.J. \& Norris C.R. 2000. Evaluation of serum feline trypsin-like immunoreactivity for the diagnosis of pancreatitis in cats. J. Am. Vet. Med. Assoc. 217(1):37-42. http://dx.doi.org/10.2460/ javma.2000.217.37. PMid:10909444.

Twedt D.C., Cullen J., McCord K., Janeczko S., Dudak J. \& Simpson K. 2014. Evaluation of fluorescence in situ hybridization for the detection of bacteria in feline inflammatory liver disease. J. Feline Med. Surg. 16(2):109-117. http://dx.doi.org/10.1177/1098612X13498249. PMid:23884636.

Van den Ingh T.S.G.A.M., Cullen J.M., Twedt D.C., Van Winkle T., Desmet V.J. \& Rothuizen J. 2006. Morphological classification of biliary disorders of canine and feline liver, p.61-76. In: Rothuizen J., Bunch S.E., Charles J.A., Cullen J., Desmet V., Szatmari V., Twedt D., Van den Ingh T., Van Winkle T. \& Washabau R. (Eds), WSAVA Standards for Clinical and Histological Diagnosis of Canine and Feline Liver Diseases. Elsevier Saunders, Edinburgh. http:// dx.doi.org/10.1016/B978-0-7020-2791-8.50009-5.

Wagner K.A., Hartmann F.A. \& Trepanier L.A. 2007. Bacterial culture results from liver, gallbladder, or bile in 248 dogs and cats evaluated for hepatobiliary disease: 1998-2003. J. Vet. Intern. Med. 21(3):417-424. PMid:17552445.

Warren A., Center S., McDonough S., Chiotti R., Goldstein R., Meseck E., Jacobsen M., Rowland P. \& Simpson K. 2011. Histopathologic features, immunophenotyping, clonality, and eubacterial fluorescent in situ hybridization in cats with lymphocytic cholangitis/cholangiohepatitis. Vet. Pathol. 48(3):627-641. http://dx.doi.org/10.1177/0300985810384409. PMid:21097715.

Weiss D.J., Gagne J.M. \& Armstrong J. 1996. Relationship between inflammatory hepatic disease and inflammatory bowel disease, pancreatitis, and nephritis in cats. J. Am. Vet. Med. Assoc. 209(6):1114-1116. PMid:8800259.

Zawie D.A. \& Garvey M.S. 1984. Feline hepatic disease. Vet. Clin. N. Am., Small Anim. Pract. 14(6):1201-1230. http://dx.doi.org/10.1016/S01955616(84)50154-5. PMid:6393553. 